\title{
Sophia de Mello Breyner Andresen e a história por João Cabral contada
}

Bruno da Costa e Silva Universidade Federal de Minas Gerais

\author{
Qual o segredo de Sevilha? \\ Saber existir nos extremos \\ como levando dentro a brasa \\ que se reacende a qualquer tempo. \\ João Cabral de Melo Neto
}

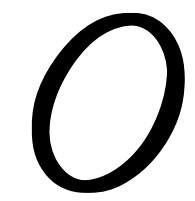

Cristo cigano, sexto livro de Sophia de Mello Breyner Andresen, publicado pela primeira vez em 1961, destaca-se como um componente singular no contexto da obra da poeta, que é considerada um dos nomes fundamentais da lírica portuguesa pós-Pessoa. Não são raras as ocasiões em que se pode observar, em estudos da crítica especializada, como, por exemplo, o de Maria de Lourdes Belchior (1986), a classificação de O Cristo cigano como uma espécie de "caso à parte" da poética andreseniana. Esta, como se sabe, prima por cantar a claridade, o mar, a revelação das coisas e a aliança do poeta com o real, bem como o movimento de regresso a tempos míticos, imemoriais, dos quais a Grécia Antiga parece servir de paradigma.

A própria Sophia não deixou de considerá-lo um caso à parte, o que pode ser constatado a partir do momento em que a autora intitula a obra posterior a O Cristo cigano de Livro sexto, rompendo, assim, com a numeração lógica de seus livros até então publicados. Em "Arte poética IV", publicada em Dual, 
Sophia define O Cristo cigano como um conjunto de vários poemas soltos, organizados num só poema longo, a partir de uma história, um tema, anterior ao poema. Segundo Luis Manuel Gaspar, editor responsável pela chamada "Edição Definitiva" da obra em destaque, isso acabaria afastando-o "[...] do conceito de 'livro' comum às outras recolhas poéticas da autora e justifica o título Livro sexto atribuído ao volume seguinte". ${ }^{1}$

A distinção de O Cristo cigano torna-se visível quando se percebe que este é um poema narrativo, do qual se depreende uma sequência de ações que obedecem a uma linearidade temporal. É pertinente assinalar, contudo, que algumas marcas próprias do fazer poético de Sophia de Mello Breyner Andresen, como a busca por um tempo inicial e a presença efetiva da claridade, nem por isso deixam de aparecer no livro em questão, o que será mostrado posteriormente.

Para utilizar uma expressão da autora, a "história anterior ao poema" que serviu de substrato para a composição dessa obra refere-se a uma lenda que perpassa o imaginário do povo sevilhano relacionada à concepção e à feitura da escultura barroca de Francisco Antonio Ruiz Gijón nomeada Cristo da la expiración, também conhecida como "O Cristo cigano", ou, ainda, "El Cachorro".

É válido observar que Sophia tomou conhecimento da lenda sevilhana pela voz de João Cabral de Melo Neto, numa visita que a poeta portuguesa fizera ao amigo, quando este exercia a carreira diplomática na Espanha. Segundo o website da Hermandad del Cachorro, ${ }^{2}$ confraria da famigerada Semana

${ }^{1}$ GASPAR, 2003, p. 33.

${ }^{2}$ Vale assinalar que o nome completo da confraria sevilhana, que sai em procissão pela cidade na Sexta-feira da Paixão com o Cristo cigano, é Pontifícia, Real e Ilustre Hermandad y Cofradía de Nazarenos del Santísimo Cristo de la Expiráción y Nuestra Madre 
Santa de Sevilha e espécie de guardiã do Cristo de la Expiración, reza a lenda que, na capital da Andaluzia do século XVII, havia um cigano, cujo apelido era El Cachorro, que muito se destacava por sua beleza. Toda noite o cigano era visto atravessando o Guadalquivir, rio que corta Sevilha, deixando, assim, o lado da cidade onde residia o seu povo para frequentar a outra margem do rio, espaço reservado à aristocracia, onde, evidentemente, os membros das tribos ciganas não costumavam ser bemvindos. Um fidalgo desconfiou de que sua mulher estava a cometer adultério com o tal cigano e, certa noite, quando viu El Cachorro transitando pelo outro lado da cidade, matou-o a facadas, tomado pelo ciúme.

Um escultor, a quem havia sido atribuída a tarefa de talhar uma escultura de um Cristo crucificado, teria presenciado a cena da agonia e morte de El Cachorro, vislumbrando, assim, a imagem perfeita para a concepção de um rosto para a escultura que lhe fora encomendada. Quando esta ficou pronta e foi exposta ao público, acredita-se que todos reconheceram a face do cigano transmutada na imagem desse Cristo em agonia. Seria esta a explicação popular para o fato de a escultura de Gijón, datada de 1682, ter passado a ser conhecida como "O Cristo cigano" ou "El Cachorro".

Se adentrarmos na seara das lendas, vale lembrar que estas podem comportar, no mínimo, duas versões. Como se sabe, as lendas são histórias pertencentes à tradição oral inerente ao imaginário de um povo. Por esse motivo, o próprio gênero, por definição, possibilitaria uma abertura a variantes. Admite-se, portanto, outra versão, na qual se afirma ter sido o próprio escultor quem teria esfaqueado El Cachorro, motivado

y Señora del Patrocinio. Disponível em: <http://www.elcachorro.org/Historia>. Acesso em: 24. out. 2011. 
pela ânsia de presenciar a agonia do belo homem a fim de, a partir dessa imagem, inspirar-se para finalmente conceber sua obra.

Em uma entrevista concedida por Sophia ao Jornal de Letras e Artes de 24 de janeiro de 1962, cujo fragmento de interesse pode ser lido na nota à edição definitiva de O Cristo cigano, há indicadores de que seria esta a versão que a autora de Livro sexto teria ouvido de João Cabral de Melo Neto durante a visita a Sevilha. Em se tratando de um diálogo entre poetas, escultores da linguagem, não parece descabido pensar que a versão que atribui o assassinato às mãos do próprio escultor tenha-lhes causado maior impacto.

Sobre este aspecto, convém ainda ressaltar que a própria teoria da literatura oferece algo enriquecedor. Quem o diz é Italo Calvino, no ensaio intitulado "A combinatória e o mito na arte da narrativa", publicado em $A$ atualidade do mito. Do estudioso que, como se sabe, muito se dedicou às investigações a respeito dos mitos, das lendas e das fábulas, é pertinente observar o seguinte excerto:

A narrativa oral primitiva, como a fábula popular que se retransmitiu quase até nossos dias, modela-se sobre estruturas fixas - poder-se-ia dizer sobre elementos préfabricados - que, permitem, no entanto, um número enorme de combinações. ${ }^{3}$

Ou, ainda, em outras palavras: "A máquina literária pode efetuar todas as permutações possíveis, com um material dado; mas o resultado poético será um efeito particular de uma dessas permutações [...]". ${ }^{4}$ No caso do poema de Sophia, escrito a partir da história contada por João Cabral, logrou-se o resultado de

${ }^{3}$ CALVINO, 1977, p. 76.

${ }^{4}$ CALVINO, 1977, p. 78. 
um artista que mata, movido por um desejo de comunhão com a morte via artes plásticas, numa aliança que, em última instância, dá-se, também, pela poesia. Para aproveitar a expressão assinalada de Calvino, esse pode ser considerado, portanto, o "efeito poético" que se depreende do livro O Cristo cigano.

Uma vez esboçados os bastidores da escrita do poema, serão levantados, nesta próxima etapa, alguns tópicos relevantes à leitura proposta para o livro em questão. Vale frisar que a intenção deste artigo, doravante, é de apenas sinalizar caminhos para possíveis leituras mais detalhadas da superfície inesgotável que é $O$ Cristo cigano.

Na edição definitiva do livro, diferentemente da primeira, consta um poema intitulado "A palavra faca", que aparece como uma espécie de apresentação, mote, ou, ainda, como sugere Clara Rocha (1994), uma dedicatória ao poeta João Cabral. Vale a pena transcrevê-lo:

A palavra faca

De uso universal

A tornou tão aguda

O poeta João Cabral

Que agora ela aparece

Azul e afiada

No gume do poema

Atravessando a história

Por João Cabral contada. ${ }^{5}$

O vocábulo faca, com efeito, permeia todo o livro. A palavra, aqui, se faz cortante e se mostra "semelhante ao brilho

${ }^{5}$ ANDRESEN, 2003, p. 7.

${ }^{6}$ ANDRESEN, 2003, p. 17. 
de uma faca nua". ${ }^{6}$ A proliferação da palavra faca, para além de remontar à arma utilizada no assassinato de El Cachorro e ao instrumento de trabalho característico do escultor, não deixa de fazer alusão, é claro, a um importante traço da poética cabralina. Vale lembrar que o poeta que cantou tanto o nordeste brasileiro, como a Sevilha que se revela cenário do poema de Sophia, possui um livro intitulado Escola das facas, no qual sugere que o fazer poético dá-se por "mão cortante e desembainhada". " É o que mostra Pedro Eiras (2007) no ensaio que recebeu o instigante título "Faca partilhada (Sophia de Mello Breyner Andresen, João Cabral de Melo Neto)", publicado em A lenta volúpia de cair.

O estudioso, que é também poeta, desenvolve a ideia de que o poema em questão não apenas anuncia a palavra faca, no sentido referencial do objeto, mas sobretudo se cria a partir da "palavrafaca", tornando-se, o próprio texto andreseniano, um "poemafaca", tal como os de Cabral. Nessa esteira argumentativa, a faca é, antes de qualquer coisa, uma questão de linguagem. Assim, o que se observa do diálogo entre a poeta portuguesa e o poeta brasileiro, nas palavras do ensaísta, é "Só faca partilhada, numa e noutra mão entregue, a mesma faca para dois, que não separa nem corta mas dedo com dedo entrelaça" ${ }^{8}$ Sobre esse mesmo aspecto, Clara Rocha (1994), por sua vez, afirma que Sophia, em OCristo cigano, "[a]o mesmo tempo em que exercita compor um pastiche do inconfundível estilo de Melo Neto, [...] celebra a poesia da evidência e da exatidão do autor de Psicologia da composição". ${ }^{\prime \prime}$

A história do escultor e do cigano, contada no livro de Sophia, é dividida em onze partes, ou, como a própria autora sugere, em onze poemas que constituirão uma unidade de

\footnotetext{
7 MELO NETO, 2008, p. 50.

${ }^{8}$ EIRAS, 2007, p. 77.

${ }^{9}$ ROCHA, 1994, p. 178.
} 
significação. No primeiro, intitulado "O escultor e a tarde", notam-se traços característicos da lírica andreseniana, os quais, com efeito, permitem que se levante a hipótese de que $O$ Cristo cigano talvez não revele uma Sophia tão diferente assim, como se observa no seguinte trecho:

\section{O tempo onde ele mora É completo e denso \\ Semelhante o fruto Interiormente aceso. ${ }^{10}$}

Como se pode perceber, junto a Pedro Eiras (2007), a voz poética invoca, aqui, uma espécie de tempo mítico, imemorial, tal qual o da lenda do Cristo cigano. Ademais, remonta-se ao tempo que Mircea Eliade (2010) denomina de "tempo forte". Do estudioso, observe-se o seguinte trecho, que parece vir a calhar para a leitura de Sophia:

O indivíduo evoca a presença dos personagens dos mitos e torna-se contemporâneo deles. Isso implica igualmente que ele deixa de viver no tempo cronológico, passando a viver no Tempo primordial, no tempo em que o evento teve lugar pela primeira vez. É por isso que se pode falar do "tempo forte" do mito: é o Tempo prodigioso, "sagrado", em que algo de novo, de forte e de significativo se manifestou plenamente. ${ }^{11}$

Em O Cristo cigano, esse tempo também se refere, em última instância, ao tempo da arte e da poesia, uma vez que nele moram o escultor e o poeta pensado por Sophia. Na perspectiva andreseniana, a criação poética acontece, sobretudo, quando se é capaz de resgatar esse tempo-espaço para ouvir os poemas que ali estão imanentes. E essa escuta dá-se através da percepção apurada que o poeta deve ter das coisas. Em "Arte poética IV", Sophia afirma:

\footnotetext{
${ }^{10}$ ANDRESEN, 2003, p. 9.

${ }^{11}$ ELIADE, 2010, p. 22, grifos do autor.
} 
Pensava que os poemas não eram escritos por ninguém, que existiam em si mesmos, por si mesmos, que eram como o elemento do natural, que estavam suspensos, imanentes. E que bastaria estar muito quieta, calada e atenta para os ouvir. Desse encontro inicial ficou em mim a noção de que fazer versos é estar atento e de que o poeta é um escutador. ${ }^{12}$

É instigante salientar, também, que, em O Cristo cigano, a tão conhecida poesia solar andreseniana, costumeiramente clara como a cal, é trespassada por uma obscuridade que parece se relacionar com a ideia da morte. Isso pode ser observado na segunda parte, intitulada "O destino": "O destino eram/os homens escuros/ que assim lhe disseram/ Tu esculpirás Seu rosto/de morte e agonia". ${ }^{13}$ Vê-se, aqui, uma espécie de voz oracular, sombria, que anuncia para o escritor aquilo que será a sua hybris, a desmesura humana referente ao assassinato que ele posteriormente irá cometer. Nota-se, diante disso, que Sophia não deixa de construir o poema obedecendo aos moldes da tragédia grega.

O escultor é caracterizado, inicialmente, como uma figura solar, uma espécie de ser intocado que habita um espaço semelhante a um locus amoenus, como se nota no seguinte excerto:

Onde estás tu, morte?

Não te posso ver:

Neste dia de Maio

Com rosas e trigos

É como se tu não

Vivesses comigo.

12 ANDRESEN, 1977, p. 78.

13 ANDRESEN, 2003, p. 11. 
A ti me enviaram

És tu meu destino

Mas diante da vida

Eu não te imagino.

A ti me enviaram

E sei que me esperas

Mas só oiço a verde

Voz das Primaveras.

Onde a tua imagem

Onde o teu retrato

Na manhã tão limpa? ${ }^{14}$

Entretanto, no decorrer do poema, o locus amoenus parece se transformar, gradativamente, em uma espécie de locus horrendus, assim como aquele ser solar, intocado, vai se convertendo em homem da escuridão e das trevas, cada vez mais obcecado com a imagem da morte. Em determinada altura, lê-se o seguinte verso: "E noite onde sem fim me afundarei".${ }^{15}$ Destaca-se, contudo, que a noite de $O$ Cristo cigano não deixa de possuir luzes próprias, mas, frise-se, são diferentes daquela luz quente e solar mencionada anteriormente. Aqui, a luz noturna é uma luz de cores frias, como se pode observar no seguinte extrato: "Ao longo do rio a noite acende suas luzes / Roxas verdes azuis". ${ }^{16}$

No que se refere a esse jogo de luz que se estabelece no livro, convém ainda assinalar que, no instante da morte do cigano El Cachorro, um clarão é refletido pela lâmina da faca, iluminando, dessa forma, a cena e o local do crime: "Brancas as paredes viram como se mata/ viram o brilho fantástico da faca/ A sua luz de

${ }^{14}$ ANDRESEN, 2003, p. 13.

15 ANDRESEN, 2003, p. 19.

16 ANDRESEN, 2003, p. 21. 
relâmpago e a sua rapidez" ${ }^{17} \mathrm{~A}$ faca desembainhada, maculada pelo sangue de El Cachorro, parece refletir, no final das contas, uma luz inspiradora que permitirá ao escultor vislumbrar a face da agonia que ele tanto procurou: "E devagar devagar o rosto surge/ o rosto onde outro rosto se retrata/ o rosto desde sempre pressentido/ por aquele que ao viver o mata" ${ }^{18}$ Como se pode perceber, há, no poema, um contraste entre luz e sombras que pode servir de tema para um estudo mais aprofundado.

Outro tópico que merece ser sinalizado refere-se a um ideário em torno da figura do Cristo que o livro inevitavelmente coloca em pauta. Sobre esse aspecto, Richard Zenith (2011) parece ter algo de interesse a dizer. Do estudioso que investigou a presença de elementos cristãos no universo da obra andreseniana, em artigo intitulado "Uma cruz em Creta: a salvação sophiana", destaca-se o seguinte parágrafo:

Não é minha intenção pôr em causa a adesão de Sophia de Mello Breyner à Igreja Católica. Talvez toda a sua poesia seja uma metáfora, ou sombra, de uma fé nesta Igreja e nos seus ensinamentos, que ela não diz claramente por não haver palavras que a consigam dizer com justiça. Aquilo que a poesia por ela deixada evidencia, no entanto, é um catolicismo que, fiel ao sentido primitivo desta palavra, se caracteriza pela sua amplitude e abertura, preocupandose pouco ou nada com doutrinas ou dogmas. A sua poesia é essencialmente liturgia, culto, oração, profecia, sendo as palavras que as compõem elos, anéis, instrumentos de religação com o reino do ser humano, o qual foi criado, segundo alguns creem, à imagem de Deus. ${ }^{19}$

\footnotetext{
17 ANDRESEN, 2003, p. 27.

18 ANDRESEN, 2003, p. 31.

19 ZENITH, 2011, p. 44.
} 
Levando em conta o trecho citado, para terminar, a faceta do Cristo que se observa no poema apresentado refere-se, antes de tudo, a um Cristo que habita as dimensões do humano. Como o próprio título sugere, um Cristo que é cigano, pobre, marginal e belo, que teve o corpo sacrificado para que, dessa maneira, pudesse surgir, com efeito, uma obra de arte. De acordo com o que se viu anteriormente, o poema estudado parece mesmo sugerir uma espécie de aliança, uma religação que, ao que tudo indica, só é possível a partir do sangue derramado. Ao fim e ao cabo, o que se salva é a arte.

\section{Referências bibliográficas}

ANDRESEN, Sophia de Mello Breyner. Dual. 2. ed. Lisboa: Moraes Editores, 1977.

ANDRESEN, Sophia de Mello Breyner. O Cristo cigano. Mindelo: Caminho, 2003.

BELCHIOR, Maria de Lourdes. O itinerário poético de Sophia. Revista Colóquio/Letras, Lisboa, n. 89, p. 36-42, jan. 1986.

CALVINO, Italo. A combinatória e o mito na arte da narrativa. In: LUCCIONI, Genie et al. A atualidade do mito. São Paulo: Duas Cidades, 1977. p. 75-80.

CECUCCI, Piero. Trazer o real para a luz: o olhar e o ouvido voltado para os seres e as coisas na poética de Sophia. Revista Colóquio/ Letras, Lisboa, n. 176, p. 15-27. jan./jun. 2011.

EIRAS, Pedro. Faca partilhada (Sophia de Mello Breyner Andresen, João Cabral de Melo Neto). In: . A lenta volúpia de cair. Vila Nova de Famalicão: Quase Edições, 2007. p. 53-77.

ELIADE, Mircea. A estrutura dos mitos. In: Mito e realidade. 6. ed. Trad. Pola Civelli. São Paulo: Perspectiva, 2010. p. 7-23. (Debates). 
GASPAR, Luis Manuel. Nota. In: ANDRESEN, Sophia de Mello Breyner. O Cristo cigano. Lisboa: Caminho, 2003. p. 33-34.

Hermandad de El Cachorro. Desenvolvido por Juan Padilla. Site oficial da Pontificia, Real y Ilustre Hermandad y Cofradía de Nazarenos del Santísimo Cristo de la Expiración y Nuestra Madre y Señora del Patrocínio. Disponível em: <www.el-cachorro.org $>$. Acesso em: 24 out. 2011.

MELO NETO, João Cabral. A escola das facas. In: . A escola das facas / Auto do Frade. Rio de Janeiro: Objetiva, 2008. p. 50.

ROCHA, Clara. Nos 50 anos de vida literária de Sophia. Revista Colóquio/Letras, Lisboa, n. 132-133, p. 165-182, abr. 1994.

ZENITH, Richard. Uma cruz em Creta: a salvação sophiana. Revista Colóquio/Letras, Lisboa, n. 176, p. 38-45, jan./jun. 2011.

\section{Resumo}

Nosso objetivo, neste artigo, consiste em propor uma leitura de $\mathrm{O}$ Cristo cigano, de Sophia de Mello Breyner Andresen, a partir dos bastidores da escrita. O referido objeto de estudo pode ser classificado como uma espécie de poema narrativo que, segundo a própria Sophia, em afirmação com a qual a crítica especializada tende a concordar, distingue-se dos demais elementos de sua obra poética. Sabe-se que este "caso à parte" da lírica andreseniana foi composto a partir de uma lenda andaluza contada por João Cabral de Melo Neto à autora de Livro sexto, numa ocasião em que os poetas se encontraram em Sevilha. Este será o ponto de partida para comentarmos O Cristo cigano, a "história anterior ao poema", bem como algumas questões pontuais que o texto nos solicita, como, por exemplo, o jogo entre luz e sombra que aparece no livro. 


\section{Abstract}

For this article, our objective consists on proposing a reading of $\mathrm{O}$ Cristo Cigano, by Sophia de Mello Breyner Andresen, from the writing's backstage. Such object of study can be classified as a kind of narrative poem which, as Sophia herself says, in affirmation whereby the specialized critics tends to agree, it is distinguished from the other elements from her poetic work. It is known that this "special case" of the Andresenian lyric was composed from an Andalusian legend told by João Cabral de Melo Neto to the author of Livro sexto, in an occasion in which the poets meet themselves in Seville. This will be the starting point to comment $O$ Cristo Cigano, the "story before the poem", as well as some punctual questions which the text requests us, like, for example, the game between light and shade that appears in the book. 